\title{
Consumer Preference and Willingness to Pay for Non-Plastic Food Containers in Honolulu, USA
}

\author{
Michele Barnes*, Catherine Chan-Halbrendt, Quanguo Zhang, Noe Abejon
}

Department of Natural Resources and Environmental Management, University of Hawaii at Manoa, Honolulu, USA. Email: "barnesm@hawaii.edu

Received September $16^{\text {th }}, 2011$; revised October $17^{\text {th }}, 2011$; accepted November $3^{\text {rd }}, 2011$.

\begin{abstract}
Expanded polystyrene (EPS), a petroleum based plastic polystyrene, has an immense environmental impact with a degradation rate of over 500 years, and is a possible human carcinogen that may cause cancer in humans. Nonetheless, EPS is the most commonly used material to produce takeout food containers, a single use item that is quickly discarded. With growing recognition of the high environmental costs of EPS products and their pressure on landfill resources, EPS food container bans have become increasingly popular in jurisdictions across the globe. Similar legislation has been introduced in the state of Hawaii, USA. However, since EPS is currently more cost effective than its alternatives, the widespread adoption of food containers produced with biodegradable materials remains a challenge. This study employs Conjoint Choice Experiment (CCE) to determine consumer preference and willingness to pay for plant-based EPS alternative takeout food containers and their various product attributes in the urban center of Honolulu, Hawaii. Latent Class Analysis (LCA) is used to cluster respondents into four distinct classes based on their observable attributes of choice. Results show that the majority of respondents $(81.0 \%)$ are in favor of a ban on EPS takeout food containers. As an alternative, the majority of respondents prefer a container constructed out of a sugarcane material (66.49\%) that is microwaveable (88.94\%), water resistant (100\%), and locally produced (51.23\%). Moreover, this study demonstrates an increase in consumer's willingness to pay for more environmentally friendly food containers, which may allow businesses to offset the costs of substituting EPS for biodegradable materials. These findings provide valuable information for farmers, manufacturers, and natural resource managers, and can help to guide decision makers when considering socially responsible and environmentally sustainable policies.
\end{abstract}

Keywords: Expanded Polystyrene (EPS), Plastic Food Containers, Conjoint Choice Experiment (CCE), Latent Class Analysis (LCA), Consumer Preference, Honolulu

\section{Introduction}

Expanded polystyrene (EPS), a form of the petroleum based plastic polystyrene, is the most commonly used material to produce takeout food containers, often used once and then discarded. However, the continued use of EPS faces a number of challenges regarding its chemical composition, inefficient recycling process, and life-cycle longevity, which make it a serious hazard to the environment [1-3].

EPS and other plastics were the fastest-growing fraction of the United States municipal waste stream from 1970 to 2003 [1], which was largely a result of a society shifting from reusable, biomass based materials to synthetic, disposable materials. In 1960, American consumers used approximately 270,000 tons of disposable plates and cups [4]. However, this number jumped three-fold to
2.07 million tons in 2009 , of which 710,000 tons, or onethird, were made with EPS [5]. Furthermore, EPS and other plastic containers and packaging increased from 120,000 tons in 1960 to 12.5 million tons in 2009, 470,000 of which were made from expanded polystyrene [5].

With a degradation rate exceeding 500 years [6], EPS has substantial long-term impacts. Although EPS can be recycled, the actual recycling process can only achieve a 40:1 compression ratio and is hindered with high transportation costs and low market value, making recycling cost-prohibitive $[4,7]$. New technology that can achieve a 90:1 compression ratio has recently been tested [8], but even if the technology is established, EPS is made from non-renewable resources and will continue to be a longterm challenge to waste-stream management and the global environment.

Due to their life-cycle longevity and widespread use, 
EPS and other plastics also currently make up 60\% - 95\% of marine debris worldwide, have been found in the stomachs of $44 \%$ of marine bird species, and have otherwise harmed 267 species of marine organisms including turtles, sea lions, and cetaceans [1]. In Hawaii, $72 \%$ of all marine debris by weight consists of plastics [9].

Moreover, styrene, the basic building block of EPS, is classified as a possible human carcinogen by the EPA and by the International Agency for Research on Cancer (IARC), and the manufacturing process of EPS has been reported by the EPA as the fifth largest creator of hazardous waste in the US [10].

Such concerns have been the basis of numerous legislative actions worldwide to limit or ban the use of EPS takeout food containers and other EPS products. In 1999, China's State Economic and Trade Commission prompted Chinese cities to enact legislation limiting the use of EPS products $[8,11]$. In the US, several cities such as Minneapolis (Minnesota), Freeport (Maine), Portland (Oregon), Malibu (California), and San Francisco (California) have banned EPS takeout food containers [12]. In 2008, Hawaii joined the states of New York and California in considering a statewide ban on EPS takeout food containers [13].

As awareness about the long-term effects of EPS and resulting EPS food container bans increase, there is a need to find cost-effective substitutes. This is particularly pertinent in the state of Hawaii. According to the Economic Census of the US Census Bureau, Hawaiian citizens consume the highest amount of takeout food per capita than any other state in the US [14]. In addition, the landfills of Hawaii are at or near capacity [15], with the overflow of waste presenting such a problem that city officials have even considered the short-term and expensive avenue of shipping trash outside of Hawaii [16]. Landfill capacity is equally a concern in other small island states, such as Taiwan, Japan, and the United Kingdom [4].

There are a number of plant-based alternative substitute materials to produce food containers such as paper, as well as other biodegradable agricultural resources such as sugarcane or corn. However, EPS is currently more cost effective than its alternatives [4], with the average takeout order costing an additional \$0.15 - \$0.20 USD to be packaged with biodegradable EPS alternative products [17]. Recognizing this, when a ban was proposed in Hawaii, the State Health Department testified that the practical impacts of substituting EPS based food containers with other materials relating to the food industry and consumers needed further examination [18].

However, there have been no published studies to date on consumer preferences and economic trade-offs among EPS alternative takeout food containers. Although, studies show that concern for the environment has become a key issue for the packaging and container industry, with an increasing number of consumers seeking ecologically minded and biodegradable products [19-23]. Therefore, a study on consumer preference for substitute food container materials would be helpful to the food and container industry and decision makers worldwide.

The purpose of this study is to determine consumer preference for more environmentally friendly plant-based EPS alternative takeout food containers in the city of Honolulu, and their willingness to pay for substitute materials and trade-offs among important food container attributes. Exploring consumer preference and willingness to pay (WTP) for more environmentally friendly food containers in Honolulu could be useful for policy makers and the container industry, particularly in Hawaii and similar small island states, as well as in other coastal and urban areas.

If, in fact, consumers prefer alternatives to EPS and are willing to pay for EPS substitutes, businesses and the takeout food container industry may be able to minimize the potentially adverse effects of an EPS ban and begin producing and offering more preferred environmentally friendly options. Moreover, an increased amount of compostable and biodegradable containers substituted for EPS containers could lessen the environmental impact of packaging, decrease dependence on foreign oil, and shrink landfill requirements [4].

The specific objectives of this study are as follows: 1) determine the public's preferences for takeout food containers made with alternative plant-based materials; 2) explore different plant-based food container market segments using latent class analysis; 3) calculate the willingness to pay (WTP) for plant-based alternative food containers and the preferred food container attributes; 4) provide market and industry implications for food container producers, policy makers, and other decision makers.

\section{Methodology}

\subsection{Research Design}

In order to investigate consumer preference and WTP for plant-based alternative takeout food containers and their attributes, a survey questionnaire was designed. The questionnaire consists of three parts: 1) information on preferences and habits related to takeout food consumption; 2) socio-economic profile of respondents; and 3) preference for alternative plant-based takeout food container attributes. For the first part of the survey, five general questions were asked: a) the frequency of takeout food consumption; b) the frequency of takeout food container use; c) the frequency of recycling or composting; d) the respondent's decision to recycle or compost their 
takeout food container if provided with that option; e) the respondents support for a local ban on EPS takeout food containers. These questions were asked in order to explore the respondent's general attitude toward recycling, composting, and the use EPS takeout food containers to determine the impact of the willingness to substitute EPS containers with alternative materials. In order to effectively communicate the purpose of the study to the respondents, EPS was referred to as 'Styrofoam ${ }^{\circledR}$ ' on the questionnaire [2].

The second part of the survey questionnaire collected socio-demographic information of respondents, while the third part utilized Conjoint Choice Experiment (CCE) to produce efficient survey takeout food container profiles that were presented to respondents to state their takeout food container choice. CCE, originally developed by Louviere and Woodworth [24], is an indirect method for studying hypothetical markets and product preferences that has been used in a number of environmental studies in recent years for valuing non-market assets [22,25-28]. CCE is based on the idea that any good can be described in terms of its product attributes, or characteristics, and the levels that these attributes take [29]. For example, takeout food containers have product attributes such as the type of material used to produce them, along with other functional food container attributes such as whether it is water resistant or microwaveable, etc. Using CCE, these attributes can be combined into different takeout food container profiles for respondents to choose from. Respondents are then given a choice set comprised of a number of tasks. Each task contains a number of profiles comprised of varying combinations of the product attributes, and respondents are asked to choose which product profile they most prefer from each task.

One of the greatest advantages of CCE is that it imitates real world decision making by forcing the respondent to make tradeoffs between product attributes [30]. Preferences for estimated part-worth utilities, or perceived benefits, for each attribute can then be estimated based on the profiles chosen by the respondent [28].

This study follows the stages of CCE design summarized by Chan-Halbrendt et al. [30], where the attributes are selected and the attribute levels assigned, followed by the construction of choice sets, data collection, and finally, data analysis. The selected attributes were based on current market options for EPS alternatives and extensive literature review of similar case studies in U.S. cities and institutions for important functional food container characteristics [8,31-33]. A summary of the selected attributes and their levels is shown in Table 1.

Product Attributes and their Levels for this study:

1) Type of Material. The purpose of this study is to determine consumer preference for takeout food containers
Table 1. EPS alternative takeout food container attributes and levels.

\begin{tabular}{ccccc}
\hline Attributes & \multicolumn{4}{c}{ Levels } \\
\hline Type of Material & Paper & Corn & Sugarcane \\
Microwaveable & Yes & No & & \\
Water Resistant & Yes & No & & \\
Locally Produced & Yes & No & & \\
Price per Container & $\$ 0.10$ & $\$ 0.20$ & $\$ 0.30$ & $\$ 0.40$ \\
\hline
\end{tabular}

made from more environmentally friendly materials than EPS. Therefore, type of material was selected as one of the attributes. Currently, plant based materials such as sugarcane and corn are being used as substitutes for EPS by companies marketing more environmentally friendly foodware products, including takeout food containers [17,34]. Paper is another alternative, which has been found to be preferred by some consumers over plastics [35]. As a result, sugarcane, corn, and paper were selected as the best choices for the materials to be used in this study. Thus, paper, corn and sugarcane made up the three levels of the 'type of material' attribute in the CCE.

2) Microwaveable. EPS food containers have been reported to leach toxic chemicals into foods under the action of microwaves [36] and are therefore not microwavable. However, being microwaveable is a commonly marketed characteristic of food containers made from EPS alternatives [37-39]. Furthermore, having a microwaveable food container may be important to consumers ordering hot takeout food that may cool before they are able to consume it. Thus, microwaveable was chosen as an attribute. This attribute consisted of only two levels: yes or no, meaning the container in question was either microwaveable or not.

3) Water Resistant. Though there are no previous publications specifically on consumer preference for takeout food container attributes, studies on packaging and containers show that functionality characteristics are important for consumers [28]. Having a water resistant container is an important basic functional characteristic of food containers that may hold any sort of liquid or sauce, and water resistance is a highly advertised attribute of food containers currently on the market [37-39]. Therefore, water resistant was included as an attribute in this study, with two levels: yes or no, meaning the container was either water resistant or not.

4) Locally Produced. Due to the extreme isolation of Hawaii and the high reliance on imported products, locally produced was included as an attribute in order to investigate its importance to consumers. This attribute consisted of two levels: yes or no, indicating that the product was either locally produced or not. 
5) Price. Product cost is known to be a key economic factor for consumer choice [27], therefore, price was included as an attribute. The levels for price were determined by reviewing the cost of currently produced EPS food container alternatives, where it was determined that $\$ 0.10$ - \$0.40 USD per container was a reasonable range for more environmentally friendly alternatives. Thus, there were 4 levels for the cost attribute: $\$ 0.10, \$ 0.20, \$ 0.30$, and $\$ 0.40$.

Previous studies have shown that age, gender, and education level can all be important factors affecting consumer preference for more environmentally friendly packaging [21]. To explore how these socio-economic factors might affect consumer choices for EPS food container alternatives, and how well the study population matches the population of Honolulu ( $75 \%$ of the population), this data was also collected from respondents.

\subsection{Statistical Design and Analysis}

When administering a CCE experiment, respondents are asked to choose from different profiles of goods made up of each attribute and one of its differing levels. In this study there are five attributes. The type of material attribute has three levels, while price has four. The remaining attributes have only two levels. Therefore, a complete factorial design including all possible combinations of attributes and levels would use $96(3 * 2 * 2 * 2 * 4)$ profiles, which is commonly accepted as being too overwhelming for respondents to evaluate and formulate decisions from. Thus, a fractional factorial design using a sample of attribute levels from the complete factorial design was used to reduce the profile number using Sawtooth Software SSI web version 6.0. The method utilized by the software is the orthogonal array most commonly used in conjoint analysis, which develops highly fractional designs by selecting profiles that balance the independent influences of all the attribute effects $[27,40]$.

Orthogonal array designs are known to be statistically efficient [41] and allow researchers to collect data on a large amount of profiles using a relatively small number of profile scenarios, thus ensuring the effects of the attributes on the respondent's preferences can still be effectively tested [30]. In total, Sawtooth Software generated 7 choice set versions of the survey, each version consisting of 12 tasks, each task containing 3 different profiles. An example of a task in a choice set is given in Table 2.

Surveys were randomly administered to Honolulu residents at various locations in the spring of 2011. An effort was made to ensure all suburbs or districts within the city were represented. Specifically, data was collected from west Honolulu, east Honolulu, downtown and in the central city center Waikiki at shopping centers and parks. Shopping centers were chosen because 1) they often
Table 2. Example of a choice set.

\begin{tabular}{cccc}
\hline Attributes & Choice A & Choice B & Choice C \\
\hline Type of Material & Sugarcane & Paper & Corn \\
Microwaveable & No & No & Yes \\
Water Resistant & No & Yes & Yes \\
Locally Produced & No & Yes & Yes \\
Price per Container & $\$ 0.20$ & $\$ 0.40$ & $\$ 0.30$ \\
\hline
\end{tabular}

contain food courts where people may be ordering takeout food, thus relating to the study, and 2) they are a central place where people of various backgrounds tend to gather naturally, thus enabling us to survey a demographically diverse sample of the city's population. Parks are also a common place that various individuals gather, and were chosen in an attempt to broaden the study to those who may not eat out often or frequent shopping centers.

The sample consisted of 244 respondents, which was determined to be sufficient for the number of attributes and levels utilized in this study according to Johnson and Orme's [42] formula for sample size for CCE.

Socioeconomic demographics of the sample are presented and compared to the census data and the State of Hawaii's population estimate for Honolulu in Table 3, which show that our sample is fairly representative of Honolulu's population. In general, gender matched well with the census data. The survey respondents were slightly younger, with $19 \%$ of our respondents in the 18 25 age group, and $45 \%$ in the 26 - 40 age group, compared to the actual $10 \%$ and $21 \%$, respectively, of Honolulu's population falling in these age groups. This discrepancy is not much of a concern for our topic, since younger age groups dine out more frequently [43] and are therefore more likely to use takeout containers. The comparison also shows that the respondents were somewhat more educated than Honolulu's population, with $45 \%$ holding an associate or bachelor's degree, and 25\% holding a graduate degree, compared to the $31.1 \%$ and $13.1 \%$, respectively, that make up Honolulu's population. However, the U.S. census data for educational attainment is only given for those in Honolulu's population that are above 25 years of age. This study also included the 18 25 age group, which may explain this discrepancy. Furthermore, this issue has had legislation introduced locally in the past, so the impact of the possibly skewed education level may not be of much concern since the topic is familiar to the general public.

The basic assumption of the Conjoint Choice Model, which is used in this study, is that when respondents are presented with different product profiles in the choice sets, they will choose the product profile, either choice A, 
Table 3. Socio-demographic comparison of the survey respondents and Honolulu's population.

\begin{tabular}{|c|c|c|c|}
\hline & Description & Honolulu Population ${ }^{1}$ & Survey Respondents \\
\hline \multirow[t]{2}{*}{ Gender } & Male & 50.6 & 53.0 \\
\hline & Female & 49.4 & 47.0 \\
\hline \multirow[t]{4}{*}{$\operatorname{Age}^{2 *}$} & $18-25$ & 13.8 & 19.0 \\
\hline & $26-40$ & 25.0 & 45.0 \\
\hline & $41-60$ & 35.6 & 25.0 \\
\hline & over 60 & 25.6 & 11.0 \\
\hline \multirow[t]{5}{*}{ Educational Attainment** } & Some High School & 5.3 & 1.0 \\
\hline & High School & 28.3 & 11.0 \\
\hline & Some College & 21.0 & 18.0 \\
\hline & Associate or Bachelor's Degree & 30.0 & 45.0 \\
\hline & Graduate Degree & 10.4 & 25.0 \\
\hline
\end{tabular}

*Percentage estimated by controlling for the exclusion of the under-18 age group to allow comparison to $100 \%$ of the sample; ** Educational attainment for Honolulu's population is presented for the above 25 age group only.

$\mathrm{B}$, or $\mathrm{C}$ in our case, that generates the highest utility. The individual's utility function can be presented as follows:

$$
U_{\text {in }}=U\left(A_{\text {in }}\right)
$$

where, $U_{i n}$, utility of the individual $n$ from the profile $i$ can be considered as a function of the attributes A. Assuming that the utility function can be divided into two parts, one deterministic observable part, $V\left(A_{\text {in }}\right)$, and one random and unobservable part, $\varepsilon\left(A_{i n}\right)$, Equation (1) can be rewritten as follows:

$$
U_{\text {in }}=V\left(A_{\text {in }}\right)+\varepsilon\left(A_{\text {in }}\right)
$$

As previously discussed, the respondent was assumed to choose the profile that gives them the highest utility, so the respondent's choice of profile $i$ rather than profile $j$ can be written:

$$
P(i \mid C)=P\left(\left(U_{i n}\right)>\left(U_{j n}\right), \text { all } j \in C\right)
$$

where $C$ is all the profiles in the choice set. Using equation (2), $\left(U_{i n}\right)>\left(U_{j n}\right)$ can be rewritten as:

$V\left(A_{i n}\right)+\varepsilon\left(A_{i n}\right)>V\left(A_{j n}\right)+\varepsilon\left(A_{j n}\right)$, and therefore:

$\varepsilon\left(A_{j n}\right)-\varepsilon\left(A_{i n}\right)<V\left(A_{i n}\right)-V\left(A_{j n}\right)$.

It follows that equation (3) can be rewritten as:

$$
\begin{aligned}
& P(i \mid C) \\
& =P\left(\varepsilon\left(A_{j n}\right)-\varepsilon\left(A_{i n}\right)<V\left(A_{i n}\right)-V\left(A_{j n}\right) \text {, all } j \in C\right)
\end{aligned}
$$

A basic assumption is that the random term $\varepsilon$ follows the Gumbel distribution [44] $F(e<t)=\exp (\exp (-t))$, where $F$ is the function, $e$ is the error term and $t$ can be

${ }^{1}$ U.S. Census Bureau, 2005-2009 American Community Survey 5-Year Estimates, Honolulu, Hawaii, 2010.

${ }^{2}$ State of Hawaii, Department of Business, Economic Development \& Tourism: 2009 Civilian Population Estimate, 2011. any number. If $A_{\text {in }}$ is a linear function of different attributes, Equation (4) can be specified as:

$$
P(i \mid C)=\frac{\exp \left(\beta L_{i n}\right)}{\sum_{j \in C} \exp \left(\beta L_{j n}\right)}
$$

where, $\beta$ is the parameter to be estimated and the $L_{n i}$ is the levels of the attributes. The simple version of equation (5) showing only the basic relationship between the respondent's choice and the attributes can be stated as:

$$
P=f(M, M I, W, L, P R)
$$

where $M$ is the type of material, $M I$ is microwavable, $W$ is water resistant, $L$ is locally produced, and $P R$ is price per container.

Latent Class Analysis (LCA) is a model-based probabilistic clustering approach that considers the heterogeneity of respondents and allows them to be grouped into separate classes based on their observable attributes of choice [45]. Equation (7), provided by Magidson [45], shows the probability of respondents in class $t$ choosing choice $j$ :

$$
P_{j . t}=\exp \left(V_{j, t}\right) / \sum_{k \in A^{\prime}} \exp \left(V_{j . t}\right)
$$

where the whole population is divided into T classes, and $t=1,2, \cdots, \mathrm{T}$.

\section{Results}

Results for the first part of our survey regarding takeout food container consumption and attitudes about EPS takeout food containers showed that $99 \%$ of the respondents surveyed eat out and use takeout food containers regularly. $97 \%$ of the respondents surveyed would recycle or compost their food container if provided with that 
option. Significantly, $81 \%$ of survey respondents stated that they are in support of a ban on EPS takeout food containers in the city of Honolulu.

Latent Gold Choice TM, Version 4.0 software was used to analyze the conjoint choice data. The first step in Latent Class Analysis is to determine the number of classes for the model. This is commonly done using Bayesian Information Criterion (BIC) [45], where the model with the lowest BIC value is chosen as the best fit model. In this case the 4-class model was chosen due to its $\mathrm{BIC}$ value. The estimated parameters for the 4-class model are shown in Table 4.

Class 1 has $37.71 \%$ of the survey respondents. This group shows a significant positive preference toward paper and sugarcane materials as opposed to corn for their takeout containers. They also show significant preferences toward microwavable and water resistant containers. A lower price was also significantly preferred.

Class 2 has $29.39 \%$ of the respondents and the majority of parameters are statistically significant. Respondents in class 2 show a significant positive preference toward sugarcane as the type of material for alternative takeout containers and a negative preference toward paper. They also show a significant positive preference toward the containers being microwavable, water resistant, locally produced; and a negative preference toward price. Demographics for respondents in class 2 revealed that this class significantly represented a younger age group.
Class 3 has $21.85 \%$ of respondents. This class significantly prefers microwavable, water resistant, locally produced takeout containers as well as a lower price. This class shows no significant preference for container materials. Demographics for respondents in class 3 showed that they have a higher education level.

Class 4 , which has $11.06 \%$ of the survey respondents, significantly prefers a water resistant takeout container and a lower price.

All the respondents show negative preferences concerning the price of takeout food containers, which is consistent with economic theory. Water resistant containers are also preferred by all four classes, indicating that all respondents consider water resistance as a basic function of takeout food containers.

Microwavable, on the other hand, is significantly preferred by class 1 , class 2 and class $3(88.94 \%$ of total respondents), indicating that a large proportion of the respondents would want to microwave their takeout food containers. Within this sub study population, respondents in class 2 and class 3 (51.23\% of respondents) show a significant preference toward locally produced containners.

The type of material used to produce takeout food containers was statistically significant for classes 1 and 2, both showing strong preferences toward sugarcane and paper.

Next, the relative importance of each attribute is cal-

Table 4. Estimated parameters of the 4-class model.

\begin{tabular}{|c|c|c|c|c|}
\hline & Class 1 & Class 2 & Class 3 & Class 4 \\
\hline Class Size & $37.71 \%$ & $29.39 \%$ & $21.85 \%$ & $11.06 \%$ \\
\hline \multicolumn{5}{|l|}{ Material } \\
\hline Corn & $-0.359 * * *$ & -0.1143 & -0.158 & 0.0045 \\
\hline Paper & $0.1206^{* * *}$ & $-0.356^{* * *}$ & 0.0156 & -0.1913 \\
\hline Sugarcane & $0.2385^{* * *}$ & $0.4703^{* * *}$ & 0.1425 & 0.1868 \\
\hline \multicolumn{5}{|l|}{ Microwaveable } \\
\hline No & $-0.1067 * * *$ & $-0.2578 * * *$ & $-1.6067 * * *$ & -0.1776 \\
\hline Yes & $0.1067 * * *$ & $0.2578 * * *$ & $1.6067 * * *$ & 0.1776 \\
\hline \multicolumn{5}{|l|}{ Water Resistant } \\
\hline No & $-0.2952 * * *$ & $-0.3763 * * *$ & $-0.6759 * * *$ & $-0.4561 * * *$ \\
\hline \multicolumn{5}{|l|}{ Locally produced } \\
\hline No & -0.0539 & $-1.5773^{* * *}$ & $-0.4719^{* * *}$ & 0.0239 \\
\hline Yes & 0.0539 & $1.5773^{* * *}$ & $0.4719^{* * *}$ & -0.0239 \\
\hline Price per Container & $-1.9649 * * *$ & $-8.6078 * * *$ & $-8.3414 * * *$ & $-23.8403 * * *$ \\
\hline Age & 0.2424 & $-0.4427 * * *$ & -0.148 & 0.3483 \\
\hline Education & -0.0083 & -0.0516 & $0.308^{* *}$ & -0.2481 \\
\hline
\end{tabular}

Note: $* * *$ significant at 0.01 level, $* *$ significant at 0.05 level. 
culated to measure how important each attribute is to each class [46] using the following formula:

$$
R I_{i}=100 \times \frac{U R_{i}}{\sum_{i=1}^{n} U R_{i}}
$$

where $R I_{i}$ is the relative importance for attribute $i$, and $U R_{i}$ is the range of utility change when attribute levels change.

Table 5 reports the relative importance of the attributes within the four different latent classes. The most important attribute varies for each class. For class 1 it is the type of the material $(28.47 \%)$, followed by water resistant $(28.13 \%)$ and price per container $(28.09 \%)$. Class 2 places the most importance on locally produced containers $(40.28 \%)$, followed by price per container (32.97\%). The takeout food container attribute most important to class 3 is microwaveable (38.66\%), followed by price per container $(30.11 \%)$. Class 4 choose price per container $(80.86 \%)$ as the most important attribute.

Willingness to pay (WTP) was also calculated, which shows the maximum amount respondents in each class are willing to pay to switch from one attribute level of the good to another. Using methods consistent with those described in Orme [47], we determined WTP using the following equation:

$$
C S=-\frac{1}{\beta m}\left(V^{1}-V^{0}\right)
$$

where, $\beta m$ is the parameter estimate of price, $V^{0}$ is the initial utility, and $V^{1}$ is the desired utility. Results showed respondents in class 1 , who consider type of material and water resistant as the most important attributes, are willing to pay $\$ 0.30$ to switch from non-water resistant to water resistant and $\$ 0.24$ and $\$ 0.06$ from corn to paper and from corn to sugarcane takeout food containers, respectively. Respondents in class 2 place locally produced as the most important attribute, and they are willing to pay $\$ 0.37$ to switch from a non-locally produced product to a locally produced product. Class 3 considers microwavable as the most important attribute, and they are willing to pay $\$ 0.39$ per container to switch from a nonmicrowavable container to a microwavable one. Respondents in class 4 were primarily concerned with price, thus their willingness to pay for a level switch is very low. For example, class 4 respondents are willing to pay only $\$ 0.04$ for switching from non-microwavable to microwavable. A summary of the WTP for each class is presented in Table 6.

\section{Discussion}

Significantly, our results show that a majority of respondents (81\%) support a local ban on EPS takeout food containers in the city of Honolulu. These results suggest
Table 5. Estimated relative importance of attributes in percent.

\begin{tabular}{ccccc}
\hline & Class 1 & Class 2 & Class 3 & Class 4 \\
\hline Type of Material & $\mathbf{0 . 2 8 4 7}$ & 0.1055 & 0.0362 & 0.0427 \\
Microwaveable & 0.1017 & 0.0658 & $\mathbf{0 . 3 8 6 6}$ & 0.0402 \\
Water Resistant & 0.2813 & 0.0961 & 0.1626 & 0.1031 \\
Locally produced & 0.0514 & $\mathbf{0 . 4 0 2 8}$ & 0.1135 & 0.0054 \\
Price per Container & 0.2809 & 0.3297 & 0.3011 & $\mathbf{0 . 8 0 8 6}$ \\
\hline
\end{tabular}

Table 6. Willingness to pay for switching from one attribute

\begin{tabular}{|c|c|c|c|c|}
\hline & Class 1 & Class 2 & Class 3 & Class 4 \\
\hline From Corn to Paper & 0.2441 & & & \\
\hline From Corn to Sugarcane & 0.0600 & 0.0960 & & \\
\hline $\begin{array}{l}\text { From Non-Microwavable } \\
\text { to Microwavable }\end{array}$ & 0.1086 & 0.0599 & 0.3852 & \\
\hline $\begin{array}{l}\text { From Non-Water Resistant } \\
\text { to Water Resistant }\end{array}$ & 0.3005 & 0.0874 & 0.1621 & 0.0383 \\
\hline $\begin{array}{l}\text { From Non-Locally } \\
\text { Produced to Locally } \\
\text { Produced }\end{array}$ & & 0.3665 & 0.1131 & \\
\hline
\end{tabular}
level to another.

that local residents may be ready and willing to pay for alternative products that focus on long-term efforts to increase sustainability and reduce pollution. This is further substantiated by our results that showed nearly every respondent (97\%) would recycle or compost their food container if provided with that option.

In general, respondents seem to prefer a takeout container made with a sugarcane material $(66.49 \%)$ that is microwaveable (88.94\%), water resistant $(100 \%)$, locally produced $(51.23 \%)$ and price competitive, as their alternative. Furthermore, all classes had a very strong preference for lower prices, which highlights the importance of being price competitive in this industry.

Specifically, classes 1 and 2, which make up the majority of our respondents $(66.49 \%)$, prefer a sugarcanebased product. Currently there are several sugarcane takeout food containers on the market that are accessible in local restaurants within Honolulu. In fact, the fiber bagasse, a byproduct of sugar production, is commonly referred as the most suitable plant-based EPS substitute, which has the least competitive use impact, is biodegradable and microwavable, and the production process is known to be less harmful than those of the other options. Moreover, in the case of Hawaii, the ban of EPS could present an economic opportunity due to the history of sugarcane production in the state, with sugarcane being an important part of the agricultural sector during last century.

It is unclear if respondents are aware of these advantages. However, class 2 may have made this connection, 
as they significantly prefer a locally produced container with a sugarcane material and are willing to pay an additional $\$ 0.08$ per container made from sugarcane, and an additional $\$ 0.37$ per container that is locally produced.

The use of paper as a substitute for EPS is disregarded by some who point to a study reporting that the production of EPS uses half as many raw materials, and much less energy than the production of paper [48]. EPS production has also been cited to release $35 \%$ fewer chemicals into the environment than the production of paper [49]. However, respondents were not given any information about EPS or the advantages and disadvantages of its alternatives prior to completing the survey and it is possible that this information is not well known. In fact, our results show that class 1 , though they ultimately prefer sugarcane takeout food containers, still prefer the use of paper over the use of corn for the type of material attribute. Surprisingly, none of our classes significantly prefer the use of a corn material for their takeout food container, though corn-based containers have been obtainable on the market recently. The use of starch-based materials, such as corn or potato, may be confronted due to the competitive use of the material for food, with opponents concerned over possible price increases of these dietary staples.

As new cities and jurisdictions are faced with environmental legislative proposals such as EPS product bans, consumer choice information such as the data and results provided in this study can assist policy makers in the development of laws that reflect the environmental preferences of the public. Additionally, this information can be used by the producers of takeout food containers when considering substituting new materials to target the market segments that consumers prefer and are willing to pay for.

\section{Conclusions}

The negative health effects and environmental concerns associated with the use of EPS are currently being widely publicized on a global scale. While EPS bans continue to be discussed and enacted globally, this study provides evidence of support for a similar ban in the city of Honolulu, with $81 \%$ of respondents in favor.

As consumers become more aware of their impact on the environment, demand for more sustainable alternatives to EPS single use items is likely to rise. Using CCE and LCA, our results offer crucial market information on the public's preference for plant-based EPS food container alternatives in the city of Honolulu. Furthermore, our results show an additional willingness to pay for more environmentally sustainable options among consumers. This willingness to pay information suggests that businesses would be able to offset any additional cost effects of a local ban on EPS takeout food containers for certain market segments.

Though the preferred food container attributes, for example the type of material, may fluctuate across states and countries, our results have global implications by showing that consumers are generally concerned with the increased use of EPS and are willing to pay for more environmentally friendly materials in the case of takeout food containers. Locally produced materials such as sugarcane and local manufacturing are important to the majority of the respondents. This could be reflective of the current sentiment of local food and job security.

This study provides valuable information for policy makers, farmers, manufacturers and natural resource managers. Through education on the effects of EPS, an increasing number of individuals will value the benefits of more sustainable alternatives greater than the damage costs of discarded EPS takeout food containers, and will be willing to switch to more environmentally friendly materials. Furthermore, this study helps to shed light on how informed consumers are concerning EPS and its alternatives, and can provide insight to policy makers on where to increase consumer information and education. Finally, making a switch to EPS alternatives could have enormous effects on landfill capacity, could reduce oceanic debris, and improve air quality. Even a small decrease in the magnitude of EPS production and waste could help to reduce the global carbon footprint and the increasing rate of environmental degradation.

\section{Acknowledgements}

The authors would like to thank Pawlowski, M. N., Reed, B., and Rosa, S., for their assistance with original concept and questionnaire development, as well as their hard work in aiding us with data collection. M.B. also thanks Arita, S. and Jaspers, K. for their helpful comments and review.

\section{REFERENCES}

[1] C. J. Moore, "Synthetic Polymers in the Marine Environment: A Rapidly Increasing, Long-term Threat," Environmental Research, Vol. 108, No. 2, 2008, pp. 131139.

doi:10.1016/j.envres.2008.07.025

[2] G. White, "The Case for Banning Styrofoam Foodservice Ware in Hawaii," 2008.

http://styrophobia.akamai-marketing.com/wp-content/upl oads/2010/11/THE-CASE-FOR-BANNING-STYROFO

AM-FOODSERVICE-WARE-IN-HAWAII-George-Whit e.pdf

[3] J. G. B. Derraik, "The Pollution of the Marine Environment by Plastic Debris: A Review," Marine Pollution Bulletin, Vol. 44, No. 9, 2002, pp. 842-852. doi:10.1016/S0025-326X(02)00220-5 
[4] K. Comstock, D. Farrell, C. Godwin and Y. Xi, "From Hydrocarbons to Carbohydrates: Food packaging of the Future," Southeast Asia Consul and Resource Co. Ltd., 2004.

http://www.sea-cr.com/Data\%20for\%20website/A2\%20c osumer $\% 20$ sec/food $\% 20$ packaging $\% 20$ of $\% 20$ the $\% 20$ fut ure.pdf

[5] EPA, "Municipal Solid Watse in the United States: 2009 Facts and Figures," U. S. E. P. Agency, Office of Solid Watse, Washington DC, 2010, p. 189.

[6] EPA, "Mid-Atlantic Municipal Solid Waste Recycling Fast Facts," 2010. http://www.epa.gov/reg3wcmd/solidwastercyclingfacts.ht $\mathrm{m}$

[7] M. Verespej, "Polystyrene Recycling Efforts Still Illusive," Waste and Recycling News, Vol. 14, 2009, p. 26.

[8] K. Betts, "Styrofoam: From Packaging to Picture Frames and Beyond," Environmental Science \& Technology, Vol. 42, 2008, pp. 5041-5041. doi:10.1021/es087184i

[9] K. J. McDermid and T. L. McMullen, "Quantitative Analysis of Small-Plastic Debris on Beaches in the Hawaiian Archipelago," Marine pollution bulletin, Vol. 48, No. 7-8, 2004, pp. 790-794. doi:10.1016/j.marpolbul.2003.10.017

[10] I. De La Fuente and J. Quan, "An Ordinance to Prohibit the Use of Polystyrene Foam Disposable Food Service Ware and Require the Use of Biodegradable or Compostable Disposable Food Service Ware by Food Venders and City Facilities," 12747 C.M.S., City of Oakland, CA, USA, 2006.

http://clerkwebsvr1.oaklandnet.com/attachments/14079.p df

[11] Z. Chen, "Finding Solutions to White Pollution," China Daily, 2006. http://english.cri.cn/3126/2008/01/11/1042@313108.htm

[12] S. M. Reck, "The Expanding Environmental Consciousness of Local Government: Municipalities that have Banned Styrofoam and the Legal Consequences," University of Bridgeport Law Review, 2003, pp. 127-145.

[13] A. Kosky, "Styrofoam Ban Kicked to the Curb," San Francisco Examiner, 2009.

http://www.syscosf.com/about/StyrofoamBanKickedtoCu rb.pdf

[14] US Census Bureau, "NAICS 722211: Limited Service Restaurants," 2007.

http://www.census.gov/econ/census02/data/industry/E722 211.HTM\#T4

[15] P. Boylan, "Hawaii Sending More Waste to Landfill," Honolulu Advertiser, 2008.

http://the.honoluluadvertiser.com/article/2008/Feb/03/ln/ hawaii802030365.html

[16] K. Dayton, "Garbage to Energy Plant for Big Island," Honolulu Advertiser, 2008.

http://the.honoluluadvertiser.com/article/2008/Mar/05/ln/ hawaii803050441.html

[17] L. Moreno, "Bio-Good to Go," Honolulu Advertiser, 2007.
http://the.honoluluadvertiser.com/article/2007/Jun/25/i1/F P706250306.html

[18] L. Arakawa, "State Plastic-Bag Ban Considered," Honolulu Advertiser, 2008.

http://the.honoluluadvertiser.com/article/2008/Feb/05/ln/ hawaii802050333.html

[19] A. Ahmed, N. Ahmed, and A. Salman, "Critical Issues in Packaged Food Business," British Food Journal, Vol. 107, No. 10, 2005, pp. 760-780. doi:10.1108/00070700510623531

[20] T. Bech-Larsen, "Danish Consumers' Attitudes to the Functional and Environmental Characteristics of Food Packaging," Journal of Consumer Policy, Vol. 19, No. 3, 1996, pp. 339-363. doi:10.1007/BF00411413

[21] J. Ali, S. Kapoor, and U. Pradesh, "Consumers' Perception on Fruits and Vegetables Packaging in India," Presented at the Annual World Symposium of the International Food and Agribusiness Management Association, Monterey, California, USA, 2008.

https://www.ifama.org/events/conferences/2008/cmsdocs/ 1004 paper.pdf

[22] C. Yue, C.R. Hall, B.K. Behe, B.L. Cambell, J.H. Dennis, and R.G. Lopez, "Are Consumers Willing to Pay More for Biodegradable Containers Than for Plastic Ones? Evidence from Hypothetical Conjoint Analysis and Nonhypothetical Experimental Auctions," Journal of Agricultural and Applied Economics, Vol. 42, No. 4, 2010, pp. 757-772.

[23] Y. Li, et al., "Eco-Impact of Shopping Bags: Consumer Attitude and Governmental Policies," Journal of Sustainable Development, Vol. 3, 2010, pp. 71-83.

[24] J. J. Louviere and G. Woodworth, "Design and Analysis of Simulated Consumer Choice or Allocation Experiments: An Approach Based on Aggregate Data," Journal of Marketing Research, Vol. 20, No. 4, 1983, pp. 350-367. doi: $10.2307 / 3151440$

[25] L. Sheild, C. Gopalakrishnan, and C. Chan-Halbrendt, "Aligning Stakeholders' Preferences with Public Trust in Managing In-stream Flow: The Case of Hawaii," International Journal of Water Resources Development, Vol. 25, No. 4, 2009, pp. 657-679. doi:10.1080/07900620903299015

[26] F. Carlsson, P. Frykblom, and C. Liljenstolpe, "Valuing Wetland Attributes: An Application of Choice Experiments," Ecological Economics, Vol. 47, No. 1, 2003, pp. 95-103. doi:10.1016/j.ecolecon.2002.09.003

[27] C. Chan-Halbrendt, D. Fang, and F. Yang, "Trade-offs between Shopping Bags Made of Non-degradable Plastics and Other Materials, Using Latent Class Analysis: The Case of Tianjin, China," International Food and Agribusiness Management Review, Vol. 12, 2009, pp. 179198.

[28] J. Rokka and L. Uusitalo, "Preference for Green Packaging in Consumer Product Choices-Do Consumers Care?" International Journal of Consumer Studies, Vol. 32, 2008, pp. 516-525. doi:10.1111/j.1470-6431.2008.00710.x 
[29] C. Chan-Halbrendt, F. Yang, L. Thomas and A. Pant, "Analysis of Farm Household Preferences in the Management of Invasive Species: The Case of Miconia in Hawaii," International Food and Agribusiness Management Review, Vol. 10, 2007, pp. 117-140.

[30] C. Chan-Halbrendt, T. Lin, F. Yang, and G. Sisior, "Hawaiian Residents' Preferences for Miconia Control Program Attributes Using Conjoint Choice Experiment and Latent Class Analysis," Environmental Management, Vol. 45, 2010, pp. 250-260. doi:10.1007/s00267-009-9415-4

[31] J. H. Zamora, "Styrofoam Food Packaging Banned in Oakland," San Francisco Chronicle, 2006. http://articles.sfgate.com/2006-06-28/news/17299537_1 styrofoam-polystyrene-yard-waste

[32] G. J. Nickels, "Nickels and Conlin Propose Green Fee on Shopping Bags, Ban on Foam," Official website for the City of Seattle, 2008. http://seattle.gov/news/detail.asp?ID $=8328 \& D e p t=40$

[33] M. Barnes, M. N. Pawlowski, M. N., B. Reed, S. Rosa, and Q. Zhang, "Willingness to Pay for Styrofoam-Alternative Food Containers in Honolulu, Hawaii," Unpublished, 2011.

[34] G. Lucas, "Polystyrene Ban: Bill Would Put California First," Capitol Weekly, 2011. http://www.capitolweekly.net/article.php?1=1\&_c=zxrx3 fbb7xxj19\&xid=zxgh3egjupdzhp\&done $=$.zxgse $210 \mathrm{bxydc}$ m\&_credir $=1313957874 \&$ c $=$ zxrx3fbb7xxj19

[35] V. Sriram and A. M. Forman, "The Relative Importance of Products' Environmental Attributes: A Cross-Cultural Comparison," International Marketing Review, Vol. 10, 1993, pp. 51-71.

[36] Harvard Health Publications, "Microwaving Food in Plastic: Dangerous or Not? “ 2006. http://www.health.harvard.edu/fhg/updates/update0706a.s html

[37] Styrofobia, 2011. http://www.styrophobia.com/bagasse.html

[38] Green Choice, 2009. http:/greenchoicevendors.com/biodegradable-fooserviceproducts/

[39] Jasa Eco, 2009. http://www.jasa-eco.com/
[40] P. E. Green and Y. Wind, "New Way to Measure Consumers' Judgments," Harvard Business Review, Vol. 53, 1975, pp. 107-117.

[41] J. J. Louviere, D. A. Hensher and J. D. Swait, "Stated Choice Methods: Analysis and Applications," Cambridge University Press, Cambridge, 2000.

[42] R. Johnson and B. Orme, "Getting the Most from CBC," Sawtooth Software Research Paper Series, 2003. http://www.sawtoothsoftware.com/education/techpap.sht $\mathrm{ml}$

[43] P. Taylor, C. Funk, and P. Craighill, "Eating More, Enjoying Less," A Social Trends Report, PEW Research Center, 2006.

[44] D. McFadden, "Conditional Logic Analysis of Qualitative Choice Behavior, "Institute of Urban \& Regional Development, University of California, 1972.

[45] J. Magidson and J. K. Vermunt, "Latent class models," In: D. Kaplan, Ed., The Sage Handbook of Quantitative Methodology for the Social Sciences, Sage Publications Inc., Thousand Oaks, 2004, pp. 175-198.

[46] C. Halbrendt, Q. Wang, C. Fraiz, and L. O'Dierno, "Marketing Problems and Opportunities in Mid-Atlantic Seafood Retailing," American Journal of Agricultural Economics, Vol. 77, 1995, pp. 1313-1318. doi: $10.2307 / 1243367$

[47] B. Orme, "Assessing the Monetary Value of Attribute Levels with Conjoint Analysis: Warnings and Suggestions," Research Paper Series, Sawtooth Software, Inc., Sequim, 2001.

[48] M. B. Hocking, "Paper Versus Polystyrene: A Complex Choice," Science, Vol. 251, 1991, pp. 504-505. doi:10.1126/science.251.4993.504

[49] Franklin Associates LTD., "Life Cycle Inventory of Polystyrene Foam, Bleached Paperboard, and Corrugated Paperboard Foodservice Products, "Eastern Research Group, Inc., Report Prepared for The Polystyrene Packaging Council: American Chemistry Council's Non-Durable Plastics Panel, 2006.

http://www.factsonfoam.com.au/web/factfoam.nsf/files/F ranklin2006.pdf/\$FILE/Franklin2006.pdf 